\title{
PARAMETER ESTIMATION BASED ON MAXIMUM LIKELIHOOD ESTIMATION METHOD FOR WEIBULL DISTRIBUTION USING DRAGONFLY ALGORITHM
}

\author{
Aynur YONAR, Department of Statistics, Faculty of Science, Selçuk University/Konya, aynursahin@selcuk.edu.tr \\ (D) https://orcid.org/0000-0003-1681-9398) \\ Nimet YAPICI PEHLIVAN*, Department of Statistics, Faculty of Science, Selçuk University/Konya, nimet@selcuk.edu.tr \\ (iD https://orcid.org/-0000-0002-7094-8097)
}

\begin{abstract}
Three-parameter (3-p) Weibull distribution is commonly used in sciences such as engineering, reliability, and renewable energy. Thus, a great number of studies have been conducted on the estimation for the parameters of this distribution. One of the mostly utilized methods for estimating the unknown parameters of the Weibull distribution in the related literature is Maximum likelihood (ML) method. In this study, a population-based novel heuristic method is proposed to use the Dragonfly Algorithm (DA) for obtaining the Maximum Likelihood estimates of three-parameter Weibull distribution. Inspired by the static and dynamic swarming behavior of the dragonflies in nature, Dragonfly algorithm has been introduced. These behaviors ensure that the algorithm has a high exploration and exploitation. An extensive Monte-Carlo simulation study is conducted to show the performance of the DA. Furthermore, the performance of DA is compared with other algorithms well known in the literature. Finally, a real data set is analyzed to show the applicability of the ML estimation based on the DA.
\end{abstract}

Keywords: Dragonfly Algorithm, Maximum Likelihood Estimation Method, Monte Carlo Simulation, Weibull Distribution.

\section{DRAGONFLY (YUSUFÇUK) ALGORİTMASI KULLANILARAK WEIBULL DAĞILIMI İÇİN EN ÇOK OLABİLİRLİK TAHMİN YÖNTEMİNE DAYALI PARAMETRE TAHMINI}

\section{Özet}

Üç parametreli (3-p) Weibull dağılımı, mühendislik, güvenilirlik ve yenilenebilir enerji gibi bilimlerde yaygın olarak kullanılmaktadır. Bu nedenle, bu dağılımın parametrelerinin tahmini üzerine birçok çalışma yapılmaktadır. En çok olabilirlik (ML) yöntemi, literatürde Weibull dağılımının bilinmeyen parametrelerinin tahmininde yaygın olarak kullanılan yöntemlerden biridir. Bu çalışmada, üç-parametreli Weibull dağılımının ML tahminlerini elde etmek için popülasyon tabanlı yeni bir sezgisel yöntem olan yusufçuk algoritmasının (DA) kullanılması önerilmiştir. Bu algoritma, yusufçukların doğadaki statik ve dinamik kümelenme davranışından esinlenilerek tanıtılmıştır. Bu davranışlar, algoritmanın yüksek bir keşif ve işletme yeteneklerine sahip olmasını sağlamaktadır. DA'nın performansını göstermek için kapsamlı bir Monte-Carlo simülasyon çalışması yapılmıştır. Ayrıca, DA'nın performansı literatürdeki diğer iyi bilinen algoritmalarla karşılaştırmıştır. Son olarak, DA'ya dayalı ML tahmininin uygulanabilirliğini göstermek için gerçek bir veri seti analiz edilmiştir.

Anahtar Kelimeler: Yusufçuk Algoritması, En Çok Olabilirlik Tahmin Yöntemi, Monte Carlo Simülasyonu, Weibull Dağılımı Cite

Yonar, A., Pehlivan, Y. N., (2021). "Parameter Estimation Based on Maximum Likelihood Estimation Method for Weibull Distribution Using Dragonfly Algorithm", Mugla Journal of Science and Technology, 7(2), 84-90.

\section{Introduction}

Weibull distribution, proposed by Weibull [1] is one of the commonly used continuous distributions in studies on lifetime and reliability, due to its flexible structure and suitability for the distribution of a wide variety of experimental observations [2]. It is applied in many fields such as engineering, quality control, physics, medicine, economics, business, etc., and is very useful in modeling [3].

A random variable $X$ which has the three-parameter Weibull distribution having location parameter $\mu$, scale parameter $\eta$, and shape parameter $\beta$, is indicated by $X \sim$ Weibull $\mu, \eta, \not$. Probability density function and cumulative distribution function of the $X \sim$ Weibull $\mu, \eta, \not A$ are given by 


$$
f_{X}(x)=\frac{\beta}{\eta}\left(\frac{x-\mu}{\eta}\right)^{\beta-1} \mathrm{e}^{-\left(\frac{x-\mu}{\eta}\right)^{\beta}} ; x \geq \mu, \eta>0, \beta>0
$$

and

$$
F_{X}(x)=1-\mathrm{e}^{-\left(\frac{x-\mu}{\eta}\right)^{\beta}} ; x \geq \mu, \eta>0, \beta>0
$$

respectively. The three-parameter Weibull distribution takes different forms according to shape parameter $(\beta)$ values. For instance, the distribution is $J$-shaped for $\beta \leq 1$ and the bell-shaped for $\beta>1$. In addition, the exponential distribution and the Rayleigh distribution are obtained for $\beta=1$ and $\beta=2$, respectively [4,5]. Parameter estimation for the three-parameter Weibull distribution is very important because of its flexible structure and very well-fitting ability in an extremely wide range of empirical observations.

One of the most widely used methods for parameter estimation is the Maximum Likelihood (ML), as ML estimators are asymptotically unbiased and have minimum variance. However, the ML estimation of the parameters for the three-parameter Weibull distribution cannot be obtained analytically and hence using the various metaheuristic methods are proposed to find the approximate values of the estimates. In recent times, the Maximum Likelihood parameter estimations for the three-parameter Weibull distribution by metaheuristic methods have been extensively studied in the literature. Abbasi et al. [6] applied the Simulated Annealing (SA) method for the ML parameter estimation of a threeparameter Weibull distribution by using three numerical examples and four sample sizes and they demonstrated that this method gives powerful and accurate results. Abbasi et al. [7] proposed a hybrid meta-heuristic based on the SA algorithm and variable neighborhood search to maximize the likelihood function for the three-parameter Weibull distribution and compared the performances of the considered methods in terms of estimation accuracy and computation time. Örkçü et al. [8] suggested the differential evolution (DE) approaches for the parameter estimation of three-parameter Weibull distribution via numerical examples and they showed that with DE, less CPU time is needed and accurate estimates are obtained. Örkçü et al. [9] obtained the ML parameter estimation of the three-parameter Weibull distribution using particle swarm optimization (PSO) approaches with different parameters, i.e. inertia weight, acceleration coefficients, particle size, and search space. The study concluded that these PSO approaches provide accurate estimates even with fewer iterations. Carneiro et al. [10] utilized the PSO method to estimate the Weibull parameters for wind resources in the Northeast Region of the Brazil and compared the PSO with five numerical methods. It has been observed that PSO provides the best performance. Yang et al. [11] used the evolutionary strategy for maximizing the likelihood function of the threeparameter Weibull distribution. Acitaş et al. [12] suggested a new PSO algorithm approach whose initial search space is constructed modified maximum likelihood estimators for the parameter estimation of the three-parameter Weibull distribution. Yonar and Yapıcı Pehlivan [13] proposed a new approach by integrating Artificial Bee Colony and Levy Flights, to get the ML estimation of the three-parameter Weibull distribution and compared this approach with some metaheuristic methods. It is concluded that the proposed algorithm produces more accurate parameter estimates.

It is not possible to talk about a general best algorithm among the above-mentioned algorithms for parameter estimation in the literature. The algorithm that gives the best parameter estimation varies according to the distribution and actual parameter values. Therefore, it is necessary to try various algorithms in the parameter estimation process.

The aim of this study is to propose an alternative method by using a novel population-based heuristic method, Dragonfly Algorithm (DA) to these methods suggested in the literature for obtaining maximum likelihood estimations of three-parameter Weibull distribution. This algorithm is inspired by dragonflies' static and dynamic swarming behaviors which allow for high levels of exploration and exploitation.

The remainder of this study is organized as follows. The Maximum Likelihood (ML) estimation method for threeparameter Weibull distribution is introduced in Section 2. The Dragonfly Algorithm (DA) is explained in Section 3. In Section 4, a comprehensive Monte-Carlo simulation study is conducted to demonstrate the performance of the DA and it is compared with some meta-heuristic methods in the literature. Also, a real dataset is analyzed to show the applicability of the ML estimation based on the Dragonfly Algorithm. As a final, conclusions are presented in Section 5.

\section{Maximum Likelihood Estimation for Three- Parameter Weibull Distribution}

Maximum Likelihood (ML) estimation method is based on maximizing the likelihood $(L)$ or $\log$-likelihood $(\ln L)$ function of any statistical distribution. Since logarithmic functions have the property of monotony, the values that maximize the $L$ and $\ln L$ functions are the same. Therefore, $\ln L$ is generally used in terms of ease of calculation. The $\ln L$ function for the three-parameter Weibull distribution is given by Eq. (3).

$$
\ln L=n \ln \left(\frac{\beta}{\eta}\right)-\sum_{i=1}^{n}\left(\left(\frac{x_{i}-\mu}{\eta}\right)^{\beta}-(\beta-1) \ln \left(\frac{x_{i}-\mu}{\eta}\right)\right)
$$


Taking the partial derivatives of the $\ln L$ according to the unknown parameters and then equalized to zero, likelihood equations are obtained. Solving these equations, the ML parameter estimations for the threeparameter Weibull distribution are obtained. However, these equations cannot be solved analytically since likelihood equations contain nonlinear functions. Therefore, it is suggested to use the Dragonfly Algorithm, which is one of the metaheuristic methods, in this study.

\section{Dragonfly Algorithm (DA)}

Dragonfly algorithm (DA) was proposed by Mirjalili [14] inspired by dragonflies' hunting and migrating behavior in nature. Hunting is called a static swarm while migration is called a dynamic swarm. In the static swarm, dragonflies fly in a narrow space to hunt in small groups. In the dynamic swarm, however, dragonflies migrate in large groups towards one direction over great distances. These movements are very similar to the exploration and exploitation phases in metaheuristic methods. While the movement of dragonflies in the static swarm forms the basis of the exploration phase, the movement in the dynamic swarm supports the exploitation phase.

The behavior of the dragonflies depends on the following five corrective patterns, namely separation, alignment, cohesion, attraction, and distraction.

Separation: It is a mechanism applied by an individual to stay away from other neighboring individuals. The separation of the individual $i$ is computed by following:

$S_{i}=-\sum_{j=1}^{N}\left(X-X_{j}\right)$

where; $X$ shows the position of the current individual, $X_{j}$ stands the position of neighboring individual $j$, and $N$ indicates the number of neighboring individuals.

Alignment: It shows how an individual matches its velocity with the velocity of other neighboring individuals. The alignment of the individual $i$ is calculated as follows:

$$
A_{i}=\frac{\sum_{j=1}^{N} V_{j}}{N}
$$

where; $V_{j}$ represents the velocity of the neighboring individual $j$.
Cohesion: It indicates the tendency of individuals towards the neighboring center of mass. The cohesion of the individual $i$ is calculated as follows:

$C_{i}=\frac{\sum_{j=1}^{N} X_{j}}{N}-X$

Attraction: It refers the tendency of individuals towards a food source. The food search of the individual $i$ is computed by:

$F_{i}=X^{+}-X$

where; $X^{+}$stands the position of the food source.

Distraction: It refers the tendency of individuals outwards an enemy. The position of enemy for the individual $i$ is calculated by:

$E_{i}=X^{-}-X$

where; $X^{-}$stands the position of the enemy.

The step vector defining the direction of the movement for the dragonflies is defined as follows:

$$
\Delta X_{t+1}=\left(s S_{i}+a A_{i}+c C_{i}+f F_{i}+e E_{i}\right)+w \Delta X_{t}
$$

where;

$s$ : separation weight,

$a$ : alignment weight,

$c$ : cohesion weight,

$f$ : food factor,

$e$ : enemy factor,

$w$ : inertia weight.

These weights enable the DA to achieve different exploration and exploitation behaviors during optimization. 
The new position of the dragonfly is computed by following:

$$
X_{t+1}=X_{t}+\Delta X_{t+1}
$$

where; $t$ indicates the current iteration.

If there are no neighboring individuals, the dragonfly's new position will be updated using Levy Flight in order to improve the dragonfly's randomness, stochastic behavior and global search capability. In this case, the new position is calculated as follows:

$X_{t+1}=X_{t}+\operatorname{Levy}(d) X_{t}$

where; $d$ defines the dimension of the position vectors. The Levy flight is computed by Eq. (12):

$\operatorname{Levy}(x)=0.01 \frac{r_{1} \sigma}{\left|r_{2}\right|^{1 / \lambda}}$

where; $r_{1}$ and $r_{2}$ indicate the random numbers in $[0,1]$. $\lambda$ is a constant and $\sigma$ is calculated by:

$\sigma=\left(\frac{\Gamma(1+\lambda) \times \sin (\pi \lambda / 2)}{\Gamma\left(\frac{1+\lambda}{2}\right) \times \lambda \times 2^{\left(\frac{\lambda-1}{2}\right)}}\right)^{1 / \lambda}$

where; $\Gamma($.$) is the gamma function.$

The DA starts by randomly generating the initial population. The algorithm updates the following until a termination criterion is satisfied for each iteration. At first, each individual in the population is assessed by using the objective function. Then, $S_{i}, A_{i}, C_{i}, F_{i}, E_{i}$ are updated using Equations (5)-(9). The step vector and the new position are subsequently updated utilizing the Equations (10)-(14). Finally, the best solution obtained in the last iteration becomes the solution of the considered problem.

\section{The Monte Carlo Simulation Study}

This section presents a Monte Carlo simulation study to demonstrate the efficiency of the DA algorithm in the ML parameter estimations for the three-parameter Weibull distribution. In this study, various real parameter values of $\theta=[2,2,2], \theta=[4,3,2]$ and $\theta=[5,2,3]$ for the threeparameter Weibull distribution and various sample sizes (n) of $100,500,1000$, and 2500 are taken similar to studies of Abbasi et al. [6] and Örkcü et al. [8]. Also, the population size $(\mathrm{N})$ is considered to be 50 and 100 judging by other studies such as Örkcü et al. [8] and Acitaş et al. [12]. The mathematical expressions of Mean values, Bias, Mean Square Error (MSE) and Deficiency (Def) criteria used in comparisons are defined as follows [15]:

$$
\begin{aligned}
& \operatorname{Mean}(\hat{\theta})=\overline{\hat{\theta}}=\sum_{i=1}^{k} \hat{\theta}_{i} / k \\
& \operatorname{Bias}(\hat{\theta})=E(\hat{\theta})-\hat{\theta}=\overline{\hat{\theta}}-\hat{\theta} \\
& \operatorname{MSE}(\hat{\theta})=\operatorname{Var}(\hat{\theta})+(\operatorname{Bias}(\hat{\theta}))^{2}
\end{aligned}
$$

$\operatorname{Def}(\hat{\mu}, \hat{\eta}, \hat{\beta})=\operatorname{MSE}(\hat{\mu})+\operatorname{MSE}(\hat{\eta})+\operatorname{MSE}(\hat{\beta})$

All the simulations are based on 1000 Monte Carlo runs. Simulation results obtained using the DA for the various parameter of the three-parameter Weibull distribution are given in Tables 1-6.

Table 1: The results of the DA for the parameters $\theta=(\mu, \eta, \beta)=(2,2,2)$ and population $\operatorname{size}(\mathrm{N})=50$

\begin{tabular}{lllll}
\hline $\mathbf{n}$ & Results & $\hat{\mu}$ & $\hat{\eta}$ & $\hat{\beta}$ \\
\hline \multirow{3}{*}{$\mathbf{1 0 0}$} & Mean & 2.0216 & 1.9650 & 1.9932 \\
& Bias & 0.0216 & -0.0350 & -0.0068 \\
& MSE & 0.0502 & 0.0785 & 0.1410 \\
& Def & 0.2697 & & \\
\hline \multirow{2}{*}{$\mathbf{5 0 0}$} & Mean & 2.0165 & 1.9765 & 1.9712 \\
& Bias & 0.0165 & -0.0235 & -0.0288 \\
& MSE & 0.0232 & 0.0321 & 0.0461 \\
& Def & 0.1014 & & \\
\hline \multirow{3}{*}{$\mathbf{1 0 0 0}$} & Mean & 2.0124 & 1.9812 & 1.9737 \\
& Bias & 0.0124 & -0.0188 & -0.0263 \\
& MSE & 0.0168 & 0.0225 & 0.0297 \\
& Def & 0.0690 & & \\
\hline \multirow{2}{*}{$\mathbf{5 0 0}$} & Mean & 2.0045 & 1.9926 & 1.9886 \\
& Bias & 0.0045 & -0.0074 & -0.0114 \\
& MSE & 0.0153 & 0.0196 & 0.0243 \\
\hline
\end{tabular}

Table 2: The results of the DA for the parameters $\theta=(\mu, \eta, \beta)=(2,2,2)$ and population $\operatorname{size}(\mathrm{N})=100$

\begin{tabular}{lllll}
\hline $\mathbf{n}$ & Results & $\hat{\mu}$ & $\hat{\eta}$ & $\hat{\beta}$ \\
\hline \multirow{3}{*}{$\mathbf{1 0 0}$} & Mean & 2.0277 & 1.9541 & 1.9767 \\
& Bias & 0.0277 & -0.0459 & -0.0233 \\
& MSE & 0.0553 & 0.0836 & 0.1517 \\
& Def & 0.2907 & & \\
\hline \multirow{2}{*}{$\mathbf{5 0 0}$} & Mean & 2.0149 & 1.9792 & 1.9798 \\
& Bias & 0.0149 & -0.0208 & -0.0202 \\
& MSE & 0.0136 & 0.0207 & 0.0306 \\
& Def & 0.0650 & & \\
\hline \multirow{3}{*}{$\mathbf{1 0 0 0}$} & Mean & 2.0150 & 1.9790 & 1.9710 \\
& Bias & 0.0150 & -0.0210 & -0.0290 \\
& MSE & 0.0126 & 0.0174 & 0.0250 \\
\hline \multirow{2}{*}{$\mathbf{2 5 0 0}$} & Def & 0.0549 & & \\
& Mean & 2.0101 & 1.9867 & 1.9805 \\
& Bias & 0.0101 & -0.0133 & -0.0195 \\
& MSE & 0.0088 & 0.0117 & 0.0157 \\
\hline
\end{tabular}


Table 3: The results of the DA for the parameters $\theta=(\mu, \eta, \beta)=(4,3,2)$ and population size $(\mathrm{N})=50$

\begin{tabular}{lllll}
\hline $\mathbf{n}$ & Results & $\hat{\mu}$ & $\hat{\eta}$ & $\hat{\beta}$ \\
\hline \multirow{3}{*}{$\mathbf{1 0 0}$} & Mean & 4.0409 & 2.9361 & 1.9739 \\
& Bias & 0.0409 & -0.0639 & -0.0261 \\
& MSE & 0.1493 & 0.2167 & 0.1603 \\
& Def & 0.5263 & & \\
\hline \multirow{5}{*}{$\mathbf{5 0 0}$} & Mean & 4.0226 & 2.9608 & 1.9693 \\
& Bias & 0.0226 & -0.0392 & -0.0307 \\
& MSE & 0.0897 & 0.1132 & 0.0635 \\
& Def & 0.2663 & & \\
\hline \multirow{4}{*0000}{} & Mean & 4.0150 & 2.9737 & 1.9741 \\
& Bias & 0.0150 & -0.0263 & -0.0259 \\
& MSE & 0.0673 & 0.0851 & 0.0474 \\
\multirow{2}{*}{$\mathbf{2 5 0 0}$} & Def & 0.1997 & & \\
& Mean & 4.0009 & 2.9936 & 1.9905 \\
& Bias & 0.0009 & -0.0064 & -0.0095 \\
& MSE & 0.0662 & 0.0821 & 0.0435 \\
\hline
\end{tabular}

Table 4: The results of the DA for the parameters $\theta=(\mu, \eta, \beta)=(4,3,2)$ and population size $(\mathrm{N})=100$

\begin{tabular}{lllll}
\hline $\mathbf{n}$ & Results & $\hat{\mu}$ & $\hat{\eta}$ & $\hat{\beta}$ \\
\hline \multirow{3}{*}{$\mathbf{1 0 0}$} & Mean & 4.0595 & 2.9151 & 1.9697 \\
& Bias & 0.0595 & -0.0849 & -0.0303 \\
& MSE & 0.0948 & 0.1540 & 0.1184 \\
& Def & 0.3673 & & \\
\hline \multirow{3}{*}{$\mathbf{5 0 0}$} & Mean & 4.0524 & 2.9338 & 1.9468 \\
& Bias & 0.0524 & -0.0662 & -0.0532 \\
& MSE & 0.0203 & 0.0344 & 0.0246 \\
& Def & 0.0792 & & \\
\hline \multirow{3}{*}{$\mathbf{1 0 0 0}$} & Mean & 4.0430 & 2.9448 & 1.9518 \\
& Bias & 0.0430 & -0.0552 & -0.0482 \\
& MSE & 0.0188 & 0.0271 & 0.0180 \\
& Def & 0.0639 & & \\
\hline \multirow{2}{*}{$\mathbf{2 5 0 0}$} & Mean & 4.0307 & 2.9605 & 1.9653 \\
& Bias & 0.0307 & -0.0395 & -0.0347 \\
& MSE & 0.0127 & 0.0175 & 0.0112 \\
\hline
\end{tabular}

Table 5: The results of the DA for the parameters $\theta=(\mu, \eta, \beta)=(5,2,3)$ and population size $(\mathrm{N})=50$

\begin{tabular}{ccccc}
\hline $\mathbf{n}$ & Results & $\hat{\mu}$ & $\hat{\eta}$ & $\hat{\beta}$ \\
\hline \multirow{4}{*}{$\mathbf{1 0 0}$} & Mean & 4.3818 & 2.6256 & 4.1209 \\
& Bias & -0.6182 & 0.6256 & 1.1209 \\
& MSE & 2.1395 & 2.2511 & 6.8280 \\
& Def & 11.2186 & & \\
\hline \multirow{4}{*}{$\mathbf{5 0 0}$} & Mean & 4.5067 & 2.5042 & 3.8277 \\
& Bias & -0.4933 & 0.5042 & 0.8277 \\
& MSE & 1.6739 & 1.7567 & 4.7200 \\
& Def & 8.1506 & & \\
\hline & Mean & 4.4788 & 2.5337 & 3.8656 \\
$\mathbf{1 0 0 0}$ & Bias & -0.5212 & 0.5337 & 0.8656 \\
& MSE & 1.7057 & 1.7905 & 4.7485 \\
& Def & 8.2447 & & \\
\hline \multirow{4}{*}{$\mathbf{2 5 0 0}$} & Mean & 4.5646 & 2.4439 & 3.7090 \\
& Bias & -0.4354 & 0.4439 & 0.7090 \\
& MSE & 1.4960 & 1.5685 & 4.0293 \\
& Def & 7.0938 & & \\
\hline
\end{tabular}

Table 6: The results of the DA for the parameters $\theta=(\mu, \eta, \beta)=(5,2,3)$ and population size $(\mathrm{N})=100$

\begin{tabular}{ccccc}
\hline $\mathbf{n}$ & Results & $\hat{\mu}$ & $\hat{\eta}$ & $\hat{\beta}$ \\
\hline \multirow{4}{*}{$\mathbf{1 0 0}$} & Mean & 4.6182 & 2.3827 & 3.7077 \\
& Bias & -0.3818 & 0.3827 & 0.7077 \\
& MSE & 1.3470 & 1.4176 & 4.3767 \\
& Def & 7.1413 & & \\
\hline \multirow{4}{*000}{} & Mean & 4.7924 & 2.2089 & 3.3459 \\
& Bias & -0.2076 & 0.2089 & 0.3459 \\
& MSE & 0.6585 & 0.6972 & 1.9154 \\
& Def & 3.2711 & & \\
\hline \multirow{4}{*}{$\mathbf{1 0 0 0}$} & Mean & 4.8439 & 2.1561 & 3.2478 \\
& Bias & -0.1561 & 0.1561 & 0.2478 \\
& MSE & 0.5454 & 0.5767 & 1.5084 \\
& Def & 2.6306 & & \\
\hline \multirow{4}{*}{$\mathbf{2 5 0 0}$} & Mean & 4.8846 & 2.1152 & 3.1755 \\
& Bias & -0.1154 & 0.1152 & 0.1755 \\
& MSE & 0.4727 & 0.4998 & 1.3133 \\
& Def & 2.2858 & & \\
\hline
\end{tabular}

As can be seen from Tables 1-6, the ML estimates obtained from the DA are generally close to the actual parameter values, and the MSE and Def values of the estimates decrease as the number of samples increases. This demonstrates the suitability of using the Dragonfly Algorithm for the Maximum Likelihood parameter estimation of the three-parameter Weibull distribution. The DA gives better results for population $\operatorname{size}(\mathrm{N})=100$ than for population size $(\mathrm{N})=50$ in most cases, except for $\theta=(2,2,2)$ and $n=100$. However, it is undesirable to have a large population size as the computation time increases as the population size increases. It is also noted from these tables that when the value of shape parameter $\beta$ is high, estimates with higher MSE and Def values are obtained. This may be due to the shape of the function.

This study also compares the parameter estimation results of the DA with those of the SA by [6], the DE [8] and the PSO [9] as shown in Table 7.

It can be clearly seen from Table 7 that PSO and DE methods produced better parameter estimates than DA, while DA gave better parameter estimates than SA according to the MSE criterion. DE gives the best parameter estimates for the actual parameter values of $\theta=[2,2,2]$ and $\theta=[4,3,2]$ while PSO gives the best parameter estimates for $\theta=[5,2,3]$. As a result, it is not possible to talk about a general method that is good for all parameter values considered. Therefore, the methods discussed in this study, except SA, can be tried as an alternative.

Detailed results of the SA, DE and PSO are not included in the result tables in order not to take up too much place. Readers can see detailed parameter estimation results from [6-9]. 
Table 7: The average ML parameter estimates of the DA, SA, DE and PSO for various real parameter vector $\theta=(\mu, \eta, \beta)$ for population size $(\mathrm{N})=100$

\begin{tabular}{|c|c|c|c|c|c|}
\hline$\theta=(\mu, \eta, \beta)$ & $\begin{array}{l}\text { Met } \\
\text { hod }\end{array}$ & & $\hat{\mu}$ & $\hat{\eta}$ & $\hat{\beta}$ \\
\hline \multirow[t]{12}{*}{$\theta=(2,2,2)$} & \multirow{3}{*}{ DA } & Mean & 2.0277 & 1.9541 & 1.9767 \\
\hline & & MSE & 0.0553 & 0.0836 & 0.1517 \\
\hline & & Def & 0.2907 & & \\
\hline & \multirow{3}{*}{$\begin{array}{l}\text { SA } \\
\text { [6] }\end{array}$} & Mean & 1.9963 & 1.9828 & 2.1448 \\
\hline & & MSE & 0.0515 & 0.0788 & 0.2190 \\
\hline & & Def & 0.3493 & & \\
\hline & \multirow{3}{*}{$\begin{array}{l}\text { DE } \\
{[8]}\end{array}$} & Mean & 2.0433 & 1.9696 & 1.9806 \\
\hline & & MSE & 0.0227 & 0.0372 & 0.0907 \\
\hline & & Def & 0.1505 & & \\
\hline & \multirow{3}{*}{$\begin{array}{l}\text { PSO } \\
\text { [9] }\end{array}$} & Mean & 1.9890 & 2.0031 & 2.0339 \\
\hline & & MSE & 0.1842 & 0.2238 & 0.3128 \\
\hline & & Def & 0.7208 & & \\
\hline \multirow[t]{12}{*}{$\theta=(4,3,2)$} & \multirow{3}{*}{ DA } & Mean & 4.0595 & 2.9151 & 1.9697 \\
\hline & & MSE & 0.0948 & 0.1540 & 0.1184 \\
\hline & & Def & 0.3673 & & \\
\hline & \multirow{3}{*}{$\begin{array}{l}\text { SA } \\
\text { [6] }\end{array}$} & Mean & 3.2764 & 3.8260 & 2.6195 \\
\hline & & MSE & 1.4024 & 1.6886 & 1.0067 \\
\hline & & Def & 4.0977 & & \\
\hline & \multirow{3}{*}{$\begin{array}{l}\text { DE } \\
{[8]}\end{array}$} & Mean & 4.0199 & 2.9652 & 2.0323 \\
\hline & & MSE & 0.0459 & 0.0895 & 0.0709 \\
\hline & & Def & 0.2063 & & \\
\hline & \multirow{3}{*}{$\begin{array}{l}\text { PSO } \\
\text { [9] }\end{array}$} & Mean & 4.0990 & 2.8653 & 1.9442 \\
\hline & & MSE & 0.0528 & 0.1023 & 0.0692 \\
\hline & & Def & 0.2242 & & \\
\hline \multirow{12}{*}{$\theta=(5,2,3)$} & \multirow{3}{*}{ DA } & Mean & 4.6182 & 2.3827 & 3.7077 \\
\hline & & MSE & 1.3470 & 1.4176 & 4.3767 \\
\hline & & Def & 7.1413 & & \\
\hline & \multirow{3}{*}{$\begin{array}{l}\text { SA } \\
\text { [6] }\end{array}$} & Mean & 3.8283 & 3.2298 & 4.8877 \\
\hline & & MSE & 2.8376 & 3.0540 & 7.3209 \\
\hline & & Def & 13.2125 & & \\
\hline & \multirow{3}{*}{$\begin{array}{c}\text { DE } \\
{[8]}\end{array}$} & Mean & 4.8360 & 2.1668 & 3.3550 \\
\hline & & MSE & 0.2033 & 0.2343 & 0.8636 \\
\hline & & Def & 1.3011 & & \\
\hline & \multirow{3}{*}{$\begin{array}{l}\text { PSO } \\
{[9]}\end{array}$} & Mean & 5.0401 & 1.9444 & 2.9258 \\
\hline & & MSE & 00666 & 0.0834 & 0.2805 \\
\hline & & Def & 0.4305 & & \\
\hline
\end{tabular}

\section{A Real Data Application}

A real data application is conducted to demonstrate the implementation of the DA for the ML parameter estimation of the three-parameter Weibull distribution. The data set which contain the failure times of 24 mechanical parts is given in Table 8 [16]:

Table 8: Data set for failure times of 24 mechanical parts

\begin{tabular}{l|l|l|l|l|l|l|l}
\hline P.No & F.time & P.No & F.time & P.No & F.time & P.No & F.time \\
\hline $\mathbf{1}$ & 30.94 & $\mathbf{7}$ & 19.08 & $\mathbf{1 3}$ & 27.47 & $\mathbf{1 9}$ & 19.40 \\
\hline $\mathbf{2}$ & 18.51 & $\mathbf{8}$ & 49.56 & $\mathbf{1 4}$ & 14.70 & $\mathbf{2 0}$ & 14.97 \\
\hline $\mathbf{3}$ & 16.62 & $\mathbf{9}$ & 17.12 & $\mathbf{1 5}$ & 14.10 & $\mathbf{2 1}$ & 22.57 \\
\hline $\mathbf{4}$ & 51.56 & $\mathbf{1 0}$ & 10.67 & $\mathbf{1 6}$ & 29.93 & $\mathbf{2 2}$ & 12.26 \\
\hline $\mathbf{5}$ & 22.85 & $\mathbf{1 1}$ & 25.43 & $\mathbf{1 7}$ & 27.98 & $\mathbf{2 3}$ & 18.14 \\
\hline $\mathbf{6}$ & 22.38 & $\mathbf{1 2}$ & 10.24 & $\mathbf{1 8}$ & 36.02 & $\mathbf{2 4}$ & 18.84 \\
\hline
\end{tabular}

The ML estimates of parameters of the Weibull distribution are obtained by SA, DE, PSO, and DA algorithms. The values of the ML estimates and $\ln L$ are given in Table 9. Furthermore, it is tested whether this data is distributed as Weibull or not via the KolmogorovSmirnov (K-S) test. The K-S test statistic values and pvalues of the K-S test statistics are also presented in Table 9.

Table 9: Parameter estimates, $\ln L$ values, K-S test statistics, and p-values of the K-S test statistics.

\begin{tabular}{l|l|l|l|l|l|l}
\hline P.No & $\hat{\mu}$ & $\hat{\eta}$ & $\hat{\beta}$ & $\ln L$ & $\begin{array}{l}\text { K-S } \\
\text { test }\end{array}$ & $\begin{array}{l}\text { p-value } \\
\text { of K-S }\end{array}$ \\
\hline SA & 9.1453 & 30.7047 & 1.1806 & -92.9171 & 0.3881 & 0.0014 \\
\hline DE & 10.0661 & 13.6261 & 1.1782 & -84.8908 & 0.0940 & 0.9831 \\
\hline PSO & 10.1104 & 13.4418 & 1.1474 & -84.8938 & 0.1028 & 0.9613 \\
\hline DA & 8.0078 & 16.1042 & 1.4021 & -86.0894 & 0.1007 & 0.9678 \\
\hline
\end{tabular}

It is clear from Table 9 that the distribution of data set for failure times is Weibull distribution except for the SA with $\mathrm{p}$-value $=0.0014$, since $\mathrm{p}$-values of the K-S test statistics are greater than $\alpha=0.05$. As a result, DE, PSO, and DA can be used to obtain the parameter estimation of the considered failure times data.

The histogram and fitted densities of data set for failure times is shown in Figure 1.

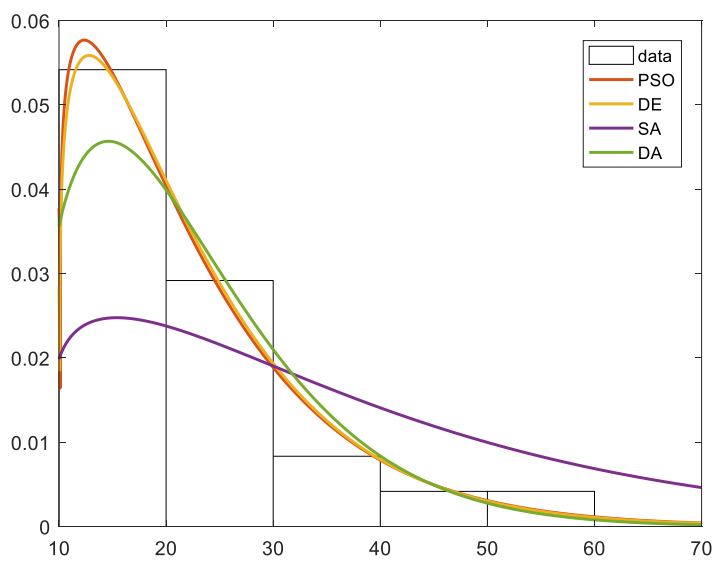

Figure 1: Histogram and fitted densities of data set for failure times

It is seen that the histogram and fitted densities presented in Figure 1 also support the above mention results.

\section{Conclusion}

In this study, Maximum Likelihood (ML) estimates of the parameters for the three-parameter Weibull distribution are obtained via Dragonfly Algorithm (DA). Monte-Carlo simulation results show that the Dragonfly Algorithm 
(DA) provides accurate estimates and it can be more preferable than Simulated Annealing (SA) for the parameter estimation of the three-parameter Weibull distribution.

Furthermore, the implementation of the DA is demonstrated by a real data analysis. In future studies, various approaches can be applied to improve the performance of the DA in order to obtain parameter estimates of different distributions.

\section{References}

[1] Weibull, W., A statistical theory of strength of materials, Stockholm: Generalstabens litografiska anstalts förlag, 1939.

[2] Nagatsuka, H., Kamakura, T. and Balakrishnan, N., "A consistent method of estimation for the threeparameter Weibull distribution", Computational Statistics Data Analysis", 58, 210-226, 2013.

[3] Almalki, S. J., and Nadarajah, S., "Modifications of the Weibull distribution: A review", Reliability Engineering System Safety, 124, 32-55, 2014.

[4] Johnson N.L., Kotz S. and Balakrishnan N., Univariate continuous distributions: New York: John Wiley \& Sons, 1994.

[5] Yonar, A., Metaheuristic approaches for estimating parameters of univariate and multivariate distributions, PhD thesis, Selçuk University: Konya,Turkey, 2020.

[6] Abbasi B., Jahromi A.H.E., Arkat J. and Hosseinkouchack M., "Estimating the parameters of Weibull distribution using simulated annealing algorithm", Applied Mathematics and Computation 183, 1, 85-93, 2006.

[7] Abbasi B., Niaki S.T.A., Khalife M.A. and Faize Y., " A hybrid variable neighborhood search and simulated annealing algorithm to estimate the three parameters of the Weibull distribution", Expert Systems with Applications, 38, 1, 700-708, 2011.

[8] Örkcü H., Aksoy E. and Dogan M.İ., "Estimating the parameters of 3-p Weibull distribution through differential evolution", Applied Mathematics and Computation 251, 211-224, 2015.

[9] Örkcü H., Özsoy V.S., Aksoy E. and Dogan M.I., "Estimating the parameters of 3-p Weibull distribution using particle swarm optimization: A comprehensive experimental comparison" , Applied Mathematics and Computation, 268, 201-226, 2015.

[10] Carneiro, T. C., Melo, S. P., Carvalho, P. C., \& Braga, A. P. D. S., "Particle swarm optimization method for estimation of Weibull parameters: a case study for the Brazilian northeast region". Renewable energy, 86, 751-759, 2016.

[11] Yang F., Ren H. and Hu Z. , "Maximum Likelihood Estimation for Three-Parameter Weibull Distribution Using Evolutionary Strategy", Mathematical Problems in Engineering, Article ID 6281781, 2019.

[12] Acitas S., Aladag C.H. and Senoglu B., "A new approach for estimating the parameters of Weibull distribution via particle swarm optimization: An application to the strengths of glass fibre data Reliability, Engineering System Safety, 183, 116-127, 2019.

[13] Yonar, A. and Pehlivan, N. Y., "Artificial bee colony with levy flights for parameter estimation of 3-p weibull distribution", Iranian Journal Science and Technology, Transaction A, 44, 3, 851-864, 2020.

[14] Mirjalili S., "Dragonfly algorithm: a new metaheuristic optimization technique for solving singleobjective, discrete, and multi-objective problems", Neural Computing Applications, 27, 4, 1053-1073, 2016.

[15] Yalçınkaya A., Şenoğlu B. and Yolcu U., "Maximum likelihood estimation for the parameters of skew normal distribution using genetic algorithm", Swarm and Evolutionary Computation, 38, 127-138, 2018.

[16] Murthy D., Xie M. and Jiang R., Weibull models, John Wiley, New York, 2004. 